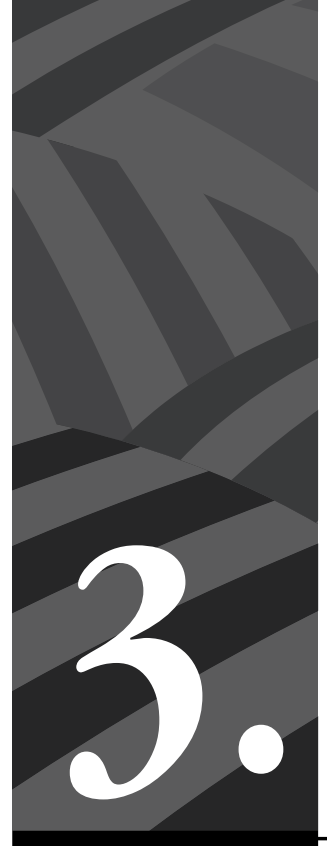

Volver a tu tierra: dispositivo pedagógico intra y entrecultural en la formación docente inicial en Oaxaca, México 


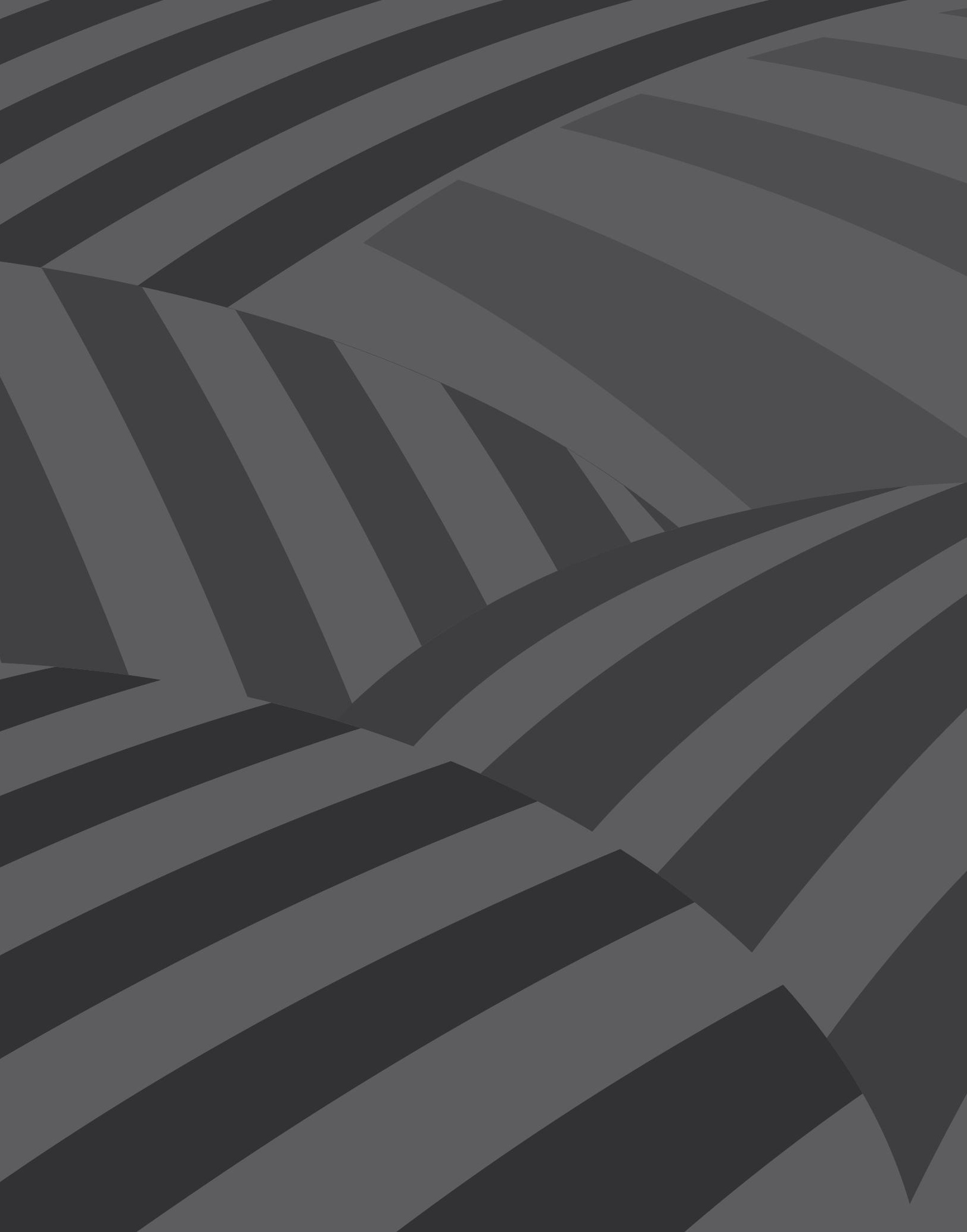




\title{
Volver a tu tierra: dispositivo pedagógico intra y entrecultural en la formación docente inicial en Oaxaca, México
}

\author{
Por Isaac Angeles Contreras*
}

Resumen: La formación docente inicial es un espacio de configuración de sujetos pedagógicos, cuya tarea será participar en el proceso de configuración de los sujetos de la sociedad del futuro; ante ese escenario y considerando al docente como sujeto productor de imaginarios y realidades sociales, se requiere de dispositivos y procesos pedagógicos y didácticos que problematicen su trayecto configurativo desde una lógica intra-entrecultural, que a la postre le permita repensarse como sujeto cultural situado/a en espacio-tiempo. Es ahí donde el dispositivo pedagógico-didáctico denominado "Volver a tu tierra", representa un reto y una oportunidad para los docentes formadores y docentes en formación, para afianzar su sentido de pertenencia geobiocultural, que valore sus prácticas sociales, así como el fortalecimiento de su identidad profesional: esta propuesta no está ajena a las críticas, conflictos y desafíos; sin embargo, representa una opción formativa que permite desplegar las potencias humanas de quienes pretenden detonar procesos de humanización en este jardín de la diversidad geobiocultural.

Palabras clave: dispositivo pedagógico, intracultural, entrecultural, educación, educación comunal y diversidad cultural.

\section{Going back to your land, intra-amidstcultural pedagogical device in the initial education of teachers in Oaxaca, Mexico}

Abstract: The pedagogical device (mechanism) "Volver a tu tierra" (Coming back to your homeland) is a didactic-pedagogical proposal for the Initial Teachers Training, based upon an intra-entrecultural perspective in order to promote a contextual education in a multi-cultural entity with communal and communitarian life practices in the presence of a homogenization education policy and cultural hegemonization; teachers, as pedagogical and cultural beings, are

* $\quad$ Docente de la Escuela Normal Rural Vanguardia Tamazulápam del Progreso, Oaxaca, México. 
responsible for generating cultural re-significance, re-assesment and re-acknowledgement processes in order to generate pedagogical and didactic processes which revitalize them, in a such way that they can reinforce the sense of belonging of the students, starting from their matrio and nosotrico context as a bio-cultural space and from other cultural matrix; on the basis of the COMUNALIDAD approach as a millenary life practice, teachers can change the cultural subordination in which indigenous peoples have been submitted.

Keywords: pedagogical device (mechanism), intra-entrecultural, education, communal education, communitarian, cultural diversity.

Cómo citar este artículo: Angeles Contreras, Isaac (2017). Volver a tu tierra: dispositivo pedagógico intra y entrecultural en la formación docente inicial en Oaxaca, México. Revista Controversia, 209, 93-109.

Fecha de recepción: 4 de agosto del 2017

Fecha de aprobación: 30 de septiembre del 2017

\section{Primeras palabras}

$\mathrm{L}$

a educación escolarizada es vital y compleja para los Estados nacionales por su posibilidad de incidencia en la configuración de sujetos; por ello, el empeño en direccionarla. El problema en México es la perspectiva de homogenización y hegemonización que se le impone, más aún, en contextos de diversidad cultural como Oaxaca.

Es en este escenario donde el docente en formación (DeF) necesita colocarse, él mismo, como resultado generador de una perspectiva cultural; por lo tanto, requiere cuestionarse sobre cuál habrá de ser su rol ante un contexto distinto al de su procedencia. Entonces, existe la necesidad de problematizar su posición como sujeto y profesional y, por lo tanto, como agente educativo. 
Esto llama al ejercicio de retrotraer su experiencia de vida, el proceso configurativo de su entorno, a partir de re-conocer y re-valorar ${ }^{1}$ los conocimientos aprendidos, los procesos, lenguajes, imágenes, códigos, ideas, relaciones e interacciones configurativas de su contexto de origen; los intereses e intenciones de los sujetos que le permitieron pensar y pensarse como sujeto singular y social en ese contexto, que a la postre direccionan la construcción de su imagen de mundo.

Se impone, así, el repensar las prácticas sociales y simbólicas que le dieron los elementos para construir su modo de Ser/Estar con sentido de pertenencia (SdP) y en determinado espacio cultural concreto e histórico, lo que representa una oportunidad de re-valoración de sus haberes como sujeto social singular; sin embargo, esto no es suficiente si no existe la posibilidad de re-significar los aportes de su espacio vital de procedencia, y a su vez, generar procesos de re-vitalización cultural. Es ahí donde el dispositivo Volver a tu tierra cobra relevancia como propuesta pedagógica didáctica intra y entrecultural, puesto que exige una inmersión en su contexto primigenio/matrio de vida, ya que es el espacio donde inició su proceso de humanización-nosotrización, lugar que lo nutrió de referentes para construir e interpretar cierta perspectiva de mundo; lo que requiere de un proceso intracultural ${ }^{2}$.

La experiencia pedagógica del dispositivo Volver a tu tierra pudo concretarse con la disposición de docentes y estudiantes de la Escuela Normal Rural Vanguardia (ENRV), ubicada en la Mixteca oaxaqueña, donde emerge e irrumpe en el contexto y proceso de la formación docente inicial (FDI) para focalizar la mirada en una arista poco abordada: la trascendencia formativa de los espacios bioculturales matrios. Esto im-

1 El prefijo re y el guion posterior indican que el concepto consecuente requiere volver a, es decir, volver a conocer, a significar.

2 "La intraculturalidad es la recuperación, revalorización y potenciamiento de las culturas de los pueblos y naciones [...] para fortalecer y reconstituir sus saberes, conocimientos, identidades, lenguas y modos de vivir, promoviendo la reafirmación de la identidad cultural”. Comunidad, 2013, p.2. 
plica reconocer que la propuesta del Estado-nación en la FDI prosigue con los procesos de colonización del pensamiento y, en consecuencia, desconfigura el sentido de pertenencia de los futuros docentes ${ }^{3}$ a partir de negar o subalternizar sus experiencias de aprendizaje primigenias.

He ahí la trascendencia de la puesta en marcha de la propuesta Volver a tu tierra; sin embargo, su concreción conlleva al ejercicio de reflexionarla, problematizarla y comunalizarla, como referente experiencial para su replanteamiento y potenciación.

\section{Reflexividad y hermenéutica de la experiencia de las futuras docentes como sujetos culturales}

Sin entrar en definiciones academicistas sobre reflexividad ${ }^{4}$ y hermenéutica $^{5}$, el ejercicio de reflexividad sobre su transitar en la vida como docentes en formación - DeF-, producto de un modo de Ser/Estar en el mundo, permitirá que, durante su desempeño profesional futuro y como producto producente de realidades, utilice herramientas metodológicas que propicien procesos de configuración de una o diversas perspectivas para mirar las realidades y sus escalas; ahí está el punto nodal del planteamiento Volver a tu tierra: no se puede ser agente cultural si no existe en el profesional un autorreconocimiento como sujeto cultural.

Aquí se considera que no se pueden favorecer procesos de re-conocimiento, re-significación y de re-vitalización cultural de unos otros, si no ha habido un proceso intracultural propio; es necesario partir del

\section{Sujeto escindido}

4 Aquí se concibe la reflexividad como un atributo de la potencia humana para pensarse en el mundo y darle sentido e intencionalidad a su Estar, lo que le permite hacer en un distanciamiento y también en proximidad por sumersión sobre su propia experiencia.

5 Concibo la hermenéutica como la disciplina de la interpretación, que nos permite comprender los textos en sus contextos respectivos. 
reconocimiento de su propia pertenencia, en sus haberes conceptuales, procesuales, actitudinales como sujetos culturales, precondición necesaria para favorecer la construcción con el otro de su noción e imagen como sujeto con SdP.

El otro existe en su diferencialidad, en la medida que hay una imagen de sí y para sí, es decir, es vital el autorreconocimiento como agente cultural -en el caso de los docentes-, para poder generar procesos de revitalización del SdP de un otro; para quienes son profesionales de la educación en el contexto oaxaqueño esto es indispensable, de ahí que se requiera que en el trayecto de la FDI se generen procesos de fortalecimiento del SdP personal y social/comunitario.

\section{Los formadores de docentes, las escuelas normales y los retos del dispositivo Volver a tu tierra}

La puesta en marcha de un dispositivo ${ }^{6}$ como Volver a tu Tierra implica una serie de situaciones que es necesario revisar. Por un lado, como docentes, ¿qué referentes conceptuales y metodológicos se tienen para orientar el proceso?, ¿qué herramientas y procesos metodológicos se tienen para aportar y apoyar a los estudiantes en el proceso de inmersión e investigación sobre su espacio vital?, ¿cómo acompañar esta intención formativa?; como institución, ¿existe una tendencia formativa en el sentido de formar agentes educativos desde una perspectiva intra y entrecultural ${ }^{7}$ ?, ¿hay apertura de los docentes para generar condiciones y gestionar los recursos económicos que requiere una práctica formativa de esta envergadura?; en referencia a las estudiantes, ¿hay un

6 Aquí se le concibe así: del latín disposǐtus (dispuesto), un dispositivo es un aparato o mecanismo que desarrolla determinadas acciones. Su nombre está vinculado a que dicho artificio está dispuesto para cumplir con su objetivo. Tomado de http:// definicion.de/dispositivo/, consultado el 17 de enero de 2013.

7 Para Sarah Corona: “'Entrecultura', [...] nombra las relaciones políticas 'entre' sujetos distintos, en el espacio público. 'Entre' no sugiere acuerdo, compenetración o entendimiento; sugiere la exposición de lo propio frente a lo ajeno en un espacio político, donde los otros se exponen y al exponerse existen”. Corona, 2007, p.13. 
compromiso personal sobre su proceso formativo?, ¿el dispositivo Volver a tu tierra es un detonante propicio para afianzar el proceso formativo como profesionales de la educación y agentes educativos, aún más, sujetos pedagógicos?; en referencia a la estructura educativa del estado de Oaxaca, ihay apertura para favorecer estos procesos formativos situados en contexto para la FDI en el estado de Oaxaca?

Lo anterior exige una revisión de nuestros haberes conceptuales y metodológicos como formadores de docentes, así como dimensionar el compromiso con la FDI para un contexto de diversidad cultural como Oaxaca; también, nos lleva a dimensionar la incidencia de la formación de docentes como tarea de las escuelas normales y, por lo tanto, nuestro compromiso profesional si se pretende formar docentes con consciencia histórica, sujetos de su tiempo y de su historia, actores y autores de los discursos y las tramas del hacer educativo en Oaxaca.

\section{Contexto y origen del dispositivo Volver a tu tierra o reandar sobre sus huellas}

Los últimos años, en la ENRV, por diversas razones, hay una constante pérdida del rigor académico. Las prácticas de formación docente (PFD) se cumplen como un proceso administrativo para la acreditación, pero es evidente el desinterés y falta de preocupación por los aprendizajes que se puedan propiciar.

En los diálogos cotidianos, los docentes mostramos desencanto por lo insulso que resulta el desarrollo de los procesos de enseñanza y aprendizaje (EyA); se infiere que esto se debe a la forma en que están planteados los trayectos formativos en el plan y programas de estudio de la LEP y que, para la DF, resultan poco significativas, sumado esto a una perspectiva homogenizante de la formación continua e inicial.

A pesar de las críticas a la FDI, pocas alternativas de su reorientación se han ensayado; se está en la insatisfacción, pero también en el marasmo 
o en un impase que no encuentra horizontes, incluso nuestra zona de confort nos lleva solo a transitar el tiempo ejecutando per se el plan de estudios; la experiencia nos enseña que no se necesita un cambio de plan de estudios, sino nociones que puedan emerger desde lo ya transitado o un planteamiento formativo que parta de otra perspectiva.

En este contexto de crítica a nuestro cotidiano hacer, se le asigna al Maestro Luis Rey Matadamas Ramírez el espacio curricular Observación y Práctica Docente III, correspondiente al V semestre de la LEP, del semestre 12-13, que comprende de agosto de 2012 a enero de 2013; como crítico del proceso performativo que las estudiantes viven durante su estancia en la ENRV, afirma:

[...] había detectado en los años que llevo en la escuela que se genera una crisis de identidad [...] se desquebraja o que se va cercenando por la influencia de otras culturas o de un proceso de culturización distinto al de su origen, se determina la crisis como una situación de vulnerabilidad que los llevar a adoptar formas culturales distintas a las de su origen en el afán de obtener aceptación social [...], cuando ocurre eso supongo que hay una identidad vulnerada ${ }^{8}$.

Lo planteado por Matadamas es compartido por la mayoría de los docentes; sin embargo, el problema es la actitud ante la situación, entonces, se impone la necesidad de incidir para que las futuras docentes puedan mirarse en este proceso y percatarse de esta realidad.

El problema no solo es en cuanto a la transformación de las estudiantes en su SdP; más bien, el cuestionamiento es: ¿cómo una futura docente, que en su FDI sufre una metamorfosis tan marcada, puede generar un SdP en sus estudiantes?, ¿qué estrategias de formación docente es necesario poner en marcha para que las futuras docentes se asuman como sujetas con SdP cultural y profesional sin caer en esencialismos?,

8 Entrevista al maestro Luis Rey Matadamas Ramírez, docente de la ENRV, 13 de marzo de 2013. 
¿cómo favorecer procesos fortalecimiento del SdP por parte de las futuras docentes?, ¿cómo generar en las estudiantes una actitud de respeto a las distintas expresiones culturales de los distintos contextos donde ejerzan como profesionales si no empiezan por sí mismas? Estas y otras interrogantes surgen al reconocer a los docentes no solo como propiciadores de procesos de aprendizaje, sino como portadores de cultura, histórica y políticamente situada en un espacio-tiempo; de tal manera que, si desde la FDI no hay un autorreconocimiento, re-valoración y re-significación de sus prácticas culturales, ya se ha vulnerado la pertenencia ante el avasallamiento de las tecnologías de la subjetivación homogenizantes.

En la intención de propiciar situaciones de autorreconocimiento cultural, donde los estudiantes tengan la oportunidad de pensarse como sujetos culturales y formar su imagen como profesionales de la educación, darles la oportunidad de presentarse ante un grupo escolar en su contexto matrio, un espacio que los vincule como sujetos educativos con los suyos/ otros y con su historia personal a cuestas, representa un conflicto que pretende detonar procesos y compromisos con su formación, experiencia que hace mirar y replantear los propios horizontes. Este es el planteamiento de Volver a tu tierra, una oportunidad desafiante en la FDI: darse la oportunidad de re-andar sobre sus huellas como personas resulta una propuesta novedosa y potencialmente formadora desde la perspectiva de fortalecer el SdP, para generar una actitud de responsabilidad y afecto por su profesión, para un espacio-tiempo específico e histórico.

\section{Autocuestionamientos, retos y expectativas}

Como detonante de otros procesos, el mismo hecho de nombrar Volver a tu tierra genera ya una serie de necesidades, actitudes, preocupaciones, dudas y más; así lo observan las estudiantes. Para Lourdes Cruz,

cuando salió esta propuesta de ir a practicar a nuestras comunidades, [...] lo primero que pensé es que tenía un gran compromiso, [...] mayor que en 
otros momentos [...] Porque regresaba de ahí de donde yo salí, de donde me vieron nacer, de donde me vieron crecer9.

Para Lisbeth Cumplido, también es un reto:

en el momento que te dicen [...] "se les va a dar la oportunidad de regresar a la escuela donde estudiaste, donde viviste los gratos momentos de tu infancia, $[\ldots]$ vas a ir como practicante, como maestra", dices: "hasta hace unos años yo estaba ahí como alumna y ahora voy a regresar”. ¿Cómo una practicante-maestra? Con niños que en gran mayoría son familiares, en el momento de estar en el salón, en la escuela: ¿Cuál va a ser el trato entre ellos y yo? ¿Cuál va a ser el respeto [...]? O [...] la gente del pueblo: ¿Qué va a decir? ${ }^{10}$.

Por su parte, el maestro Matadamas considera que

primero es un choque, porque se remiten a un espacio donde ellas han actuado, [...] interaccionado [...], porque finalmente asumen funciones, roles asignados en la comunidad [...] eso las lleva a interaccionar con otros sujetos que asumen esos roles o distintos en el marco del espacio social, familiar, comunitario, escolar, grupos de amigos, religioso, etc. Entonces eso les permite hacer un cotejo de la oferta social en su aspiración y sus propios procesos que le han dado estructura ${ }^{11}$.

Volver a tu tierra, entonces, se convierte en un detonante, en un incentivo tanto para las estudiantes como para los propios docentes. Para el profesor Aristeo Pablo,

9 Entrevista a Lourdes Cruz Martínez, estudiante de la ENRV, 14 de marzo de 2013.

10 Entrevista a Lisbeth Cumplido, estudiante de la ENRV, 14 de marzo de 2013.

11 Entrevista al maestro Luis Rey Matadamas Ramírez, responsable de Observación y Práctica Docente III, ENRV, 13 de marzo de 2013. 
por mi parte, empecé a pensar en qué podían lograr yendo a su tierra, cuando acordamos [...] qué pueden llevar como conocimientos, pensé que iba a haber más compromiso [...] empezamos a trabajar varios aspectos en educación artística; pensamos recuperar la danza, la música, sobre los monumentos históricos [...], ese fue mi enfoque [...], preparamos esa parte ${ }^{12}$.

Así, tanto para docentes como para estudiantes, Volver a tu tierra se torna en un desafío, tal como plantea el profesor Aristeo; por parte de las estudiantes, el retorno a su espacio matrio en un rol de docentes ya no solo se da como una persona común que transita por la comunidad, con sus trayectos y diálogos cotidianos, sino que las coloca en un escenario diferente, porque están en otras condiciones, inclusive, de retos ante su historia personal y familiar; en ese tenor, Fátima dice:

Por mi parte, era estar ahí en una condición de mostrar que a pesar de mi situación económica y de mujer, se puede tener una carrera, que no por ser mujer no puedes salir y elegir lo que quieres ser; eso, porque en mi comunidad existe muy fuerte el machismo ${ }^{13}$.

Entonces, poner en marcha el dispositivo Volver a tu Tierra no es cumplir con un componente más del currículum, realizando las prácticas de FDI como un acercamiento a su futuro campo laboral, además es un detonante que lleva a pensar al docente formador sobre las herramientas metodológicas y dispositivos pedagógico-didácticos que es necesario generar con los estudiantes, para que puedan diseñar estrategias y dispositivos pedagógico-didácticos en su ejercicio profesional dentro de los distintos contextos y realidades.

Como estudiantes, los retos son diversos, empezando por mirarse en su historia personal como proceso y producto de su contexto matrio; en cuanto a la identidad personal/sentido de pertenencia, permite configurar

12 Entrevista al profesor Aristeo Pablo Galán, docente de la ENRV, 19 de marzo de 2013.

13 Entrevista a Fátima Urieta González, estudiante de la ENRV, 09 de marzo de 2013. 
y afianzar su imagen especular futura como profesional de la educación, desde los referentes empíricos de su entorno así como de lo que se ha apropiado en la escuela normal; aún más, implica situarse en la mirada de su comunidad como persona pública, donde el contexto le recuerda su trayecto personal y los procesos en donde ha sido actora y testigo, o ser un hilo de ese entramado social; así lo mira Lourdes Cruz:

me reconocí en esos niños, aunque en tiempos diferentes, el contexto, [...] los momentos que yo viví de niñita [...], me identifique mucho con los niños, miré como llegaban con sus caritas sucias, [...] tenía niños que caminaban media hora para llegar a la comunidad ${ }^{14}$.

No implica solamente formar en el reconocimiento de su SdP cultural y fortalecer su vocación profesional; el ejercicio también es formativo en cuanto a asignaturas y contenidos/competencias profesionales no siempre fáciles de abordar en la escuela primaria, como la Historia; la futura docente se rencuentra con su propia historia y, por lo tanto, en la necesidad de aprender de ella, repensarla, de tal manera que lo que encuentre e investigue le sea significativo para su ejercicio profesional. En ese sentido, el Maestro Moysés Cruz, responsable de Historia y su Enseñanza, plantea:

se les explicó que era necesario trabajar a través del pueblo y entender primeramente que para comprender la historia es necesario comprender primeramente la historia de su pueblo, de su comunidad y en tiempos cortos, primeramente tenían una problemática: comprender la historia, que es su historia también, y hacerla agradable ${ }^{15}$.

De la misma manera, en Ciencias Naturales, era pensar en lo que su espacio matrio produce, genera, procesa en cuanto a alimentos, artesanías

14 Entrevista a Lourdes Cruz Martínez, estudiante de la ENRV, 14 de marzo de 2013.

15 Entrevista al maestro Moysés Cruz, profesor de Historia y su Enseñanza de la ENRV, 13 de marzo de 2013. 
y otros que se convierten en un pretexto ideal para el aprendizaje situado; de la misma manera se observa en otras materias o asignaturas que se abordan en la escuela primaria.

Entonces, Volver a tu tierra es reto y oportunidad, historia y proceso, recuerdo y horizonte; la imagen en proyección de sus esperanzas y expectativas en construcción que genera compromiso, así lo dice Lisbeth Cumplido:

es una preocupación, porque la imagen que tú les des sea la más agradable, [...] es una responsabilidad y es un compromiso no solo contigo, sino con ellos, con tu pueblo, con tu gente [...] ser maestro [...] no es cualquier cosa, y que es algo que te la tienes que creer, implica muchas cosas, que no las crees, o no las veas, hasta que lo vives ${ }^{16}$.

Las experiencias narradas nos dejan ver la trascendencia de Volver a tu tierra como dispositivo pedagógico para la FDI. Para los docentes formadores, representa un compromiso con la sociedad que se vuelve demandante de docentes vinculados con su entorno, por lo que esta ruta parece tener horizontes; con dicho ejercicio, la esperanza halla un sitio de dónde asirse. El futuro es una construcción desde el pensamiento disruptivo, solo que los actores del proceso deben confluir en interés y expectativas.

\section{Volver a tu tierra y los dispositivos comunitarios}

En este sentido, el dispositivo Volver a tu tierra permite reconocer los factores sociales que inciden en el contexto de la práctica vivenciada, así como sus procesos organizativos, para que las comunidades transiten de ser sujetos a educar a sujetos partícipes de la generación del imaginario a construir en el proceso educativo; entonces, el rol que asume la comunidad es ser parte decisoria del proceso, en donde la asamblea es

16 Entrevista a Lisbeth Cumplido, estudiante del VI semestre de la LEP en la ENRV, 16 de marzo de 2013. 
un dispositivo para crear las condiciones de posibilidad para el trabajo y vinculación escuela-comunidad. Al respecto, dice Estefanía:

Al llegar a la Escuela Primaria, le planteé al director la forma de trabajo, le propuse que teníamos que hacer una asamblea de padres de familia para plantearles la forma de trabajo, que teníamos la necesidad de contar con el apoyo de los padres para desarrollar el proyecto que realizaríamos con los niños; ya en la asamblea, ellos estuvieron de acuerdo y, pues, cuando presentamos los resultados, estaban muy contentos ${ }^{17}$.

La asamblea, como dispositivo, permite poner en sintonía a los docentes y a los padres de familia, construye colectivamente horizontes y expectativas, y genera aprendizaje colectivo, el que se contrapone a la formación individualista, competitiva y excluyente propuesta desde la oficialidad.

En cuanto a la organización interna, la academia de semestre de docentes y estudiantes, al conformarse en asamblea, convierte este espacio de encuentro en un lugar privilegiado y potenciador de la FDI, puesto que la socialización/comunalización encuentra un lugar para favorecer la mirada e interés colectivo, así lo considera Matadamas:

la asamblea es un dispositivo de acuerdo, un dispositivo que puede ir más allá del currículum [...], es un dispositivo social que permite, primero: mirar al otro como un ser capaz de aportar en los procesos educativos; segundo: mirarlas como seres heterogéneas y plurales en las intenciones ${ }^{18}$.

Más allá de la formalidad de la asamblea como dispositivo comunal, es también un espacio de aprendizaje colectivo, de discusión y, más aún, un lugar privilegiado para la fusión de horizontes, en el sentido que Gadamer (2003, p.377) plantea: la tradición y la experiencia que

17 Entrevista a Estefanía de la Cruz, estudiante de la ENRV, 19/03/13.

18 Entrevista al maestro Luis Rey Matadamas Ramírez, 13/03/13. 
portan los docentes formadores con la inquietud, ímpetu y esperanzas de quienes están en proceso formativo.

La asamblea es catalizadora de los sueños y utopías de los partícipes y actores del proceso, es donde halla cuerpo el autor colectivo de la esperanza hecha palabra y discurso, para después objetivarse en la acción colectiva que hace posible la acción pensada; de ahí el potencial pedagógico de la asamblea de docentes y estudiantes como dispositivo comunal/comunitario.

\section{A manera de conclusión}

Las condiciones y situaciones que plantea el escenario geopolítico global del momento llaman a construir desde abajo los mundos posibles, que ayuden a resistir el avasallamiento de la homogenización y hegemonización del modelo neoliberal depredador que arrasa imaginarios, mundos, culturas y la naturaleza toda.

Sin embargo, esa construcción desde abajo no es posible mientras no se reconozca a la otredad en su diversidad y diferencia, construida histórica y políticamente; la homogenización y hegemonización del mundo como propuesta colonizadora solo es posible en el imaginario de quien pretende dominar, controlar y expoliar a un otro.

Como docentes, nuestra tarea es favorecer el despliegue de las potencias humanas. Para esto se deben considerar las condiciones bioculturales de los sujetos del proceso, así como sus características personales, inteligencias, intereses y prácticas sociales construidas histórica y políticamente.

En ese contexto de acción, el dispositivo pedagógico-didáctico Volver a tu Tierra es una propuesta de trascendencia para la FDI, si se está en la lógica de la búsqueda de un mundo donde la diversidad sea la característica humana más reconocida, favorecida y festejada; a contracorriente de lo que se promueve, gestiona y se propala a través de las tecnologías de la subjetivación. 
Hoy, quizá más que ayer, es imperativo luchar por un mundo donde quepan muchos mundos.

\section{Referencias}

Bourdieu, Pierre (2003). El oficio de científico. Ciencia de la ciencia y reflexividad. Traducción de Joaquín Jordé. Barcelona: Anagrama.

Corona, Sarah (2007). Entre voces... Fragmentos de educación "entrecultural". Guadalajara: Universidad de Guadalajara.

Gadamer, Georg-Hans (2003). Verdad y Método. Tomo I, Salamanca: Ediciones Sígueme.

Meneses Jiménez, María Teresa (2007). La reflexividad como herramienta de investigación cualitativa (III). Nure Investigación, (32). Recuperado de: http:// www.nureinvestigacion.es/OJS/index.php/nure/article/view/363

Ministerio de Educación Bolivia (2013, abril). Comunidad, 3(3). Recuperado de http://www.educabolivia.bo/files/SEPARATA_11.pdf 